\title{
Partículas modais em alemão e seus equivalentes funcionais em português brasileiro: proposta de análise e classificação para o uso
}

\author{
[Modal particles and their functional equivalents in Brazilian Portuguese: analyzing \\ modal elements in a cross-linguistic perspective] \\ http://dx.doi.org/10.11606/1982-88372340166
}

\section{Marceli Cherchiglia Aquino ${ }^{1}$ Poliana Coeli Costa Arantes ${ }^{2}$}

\begin{abstract}
In this paper we intend to perform a contrastive analysis of modal particle occurrences (hereinafter PM) in German, Catalan, Croatian, French and English, proposing a class of PM for Brazilian Portuguese. We start from the theoretical framework based on pragmatics and functionalist theories as support. Our main objective is to defend the existence of PMs in Brazilian Portuguese, being they linguistic-discursive resources used with the function of modifying nonexplicit information during the interaction. In this sense, PMs would activate assumptions in utterances based on nuclear meanings. This is an unprecedented study for proposing analysis of words and phrases that have not yet been classified as such in Portuguese-Brazilian grammars. This study is justified by the difficulty that these PM present both for teaching additional language and for translation. Investigating and describing German PMs and their functional equivalents in Portuguese can therefore provide avenues for understanding important pragmatic issues for communicative exchanges and their uses in the classroom. Finally, we hypothesize that, although there is a clear difference in the classification of these particles in many languages, the communicative functions of German PMs may find similar interpretative and even functional equivalents in Brazilian Portuguese.
\end{abstract}

Keywords: German modal particles; modality in Portuguese language; contrastive analysis.

Resumo: Neste artigo intencionamos realizar uma análise contrastiva de ocorrências de partículas modais (doravante PM) em alemão, catalão, croata, francês e inglês, propondo uma classe de PM para o português brasileiro. Partimos de referencial teórico com base na pragmática e em teorias funcionalistas como suporte. Nosso principal objetivo é defender a existência de PMs no português brasileiro, sendo elas recursos linguístico-discursivos utilizados com a função de modalizar informações não explícitas durante a interação. Nesse sentido, as PMs ativariam pressupostos nas enunciações baseados em significados nucleares. Trata-se de estudo inédito por propor análises de palavras e locuções que ainda não foram classificadas como tal em gramáticas

\footnotetext{
${ }^{1}$ Universidade de São Paulo, Avenida Professor Luciano Gualberto, 403, Cidade Universitária, Butantã, São Paulo, SP, 05508-010, Brasil. E-mail: marceli.c.aquino@gmail.com. ORCID: 0000-0003-0518-7639

${ }^{2}$ Universidade do Estado do Rio de Janeiro, Rua São Francisco Xavier, 524, Maracanã, Rio de Janeiro, RJ, 20550-900, Brasil. E-mail: polianacoeli@yahoo.com.br. ORCID: 0000-0003-4880-5767
}

\section{(cc) BY-NC}

Pandaemonium, São Paulo, v. 23, n. 40, maio-ago. 2020, p. 166-190 
AQUINO, M. C.; ARANTES, P. C. C. - Partículas modais em alemão e seus equivalentes funcionais

luso-brasileiras, salvo algumas poucas exceções. O presente estudo justifica-se pela dificuldade que essas PM apresentam tanto para o ensino de língua adicional, quanto para a tradução. A investigação e descrição das PMs alemãs e seus equivalentes funcionais em português, podem, portanto, oferecer caminhos para a compreensão de questões pragmáticas importantes para as trocas comunicativas e seus usos em sala de aula. Finalmente, levantamos a hipótese de que, embora exista uma evidente diferença de classificação dessas partículas em muitas línguas, as funções comunicativas das PMs em alemão podem encontrar semelhantes interpretativos e até equivalentes funcionais em português brasileiro.

Palavras-chave: partículas modais alemãs; modalidade em língua portuguesa; análise contrastiva.

\section{Introdução}

As partículas modais (doravante PMs) são uma classe de palavras que foram investigadas com maior frequência nas línguas germânicas, mas ao contrário do que tem sido visto em alguns trabalhos, a existência desses elementos lexicais parece não ser exclusiva do idioma alemão, sendo encontrada também, mesmo contrariando alguns autores alemães, em língua portuguesa (SAID Ali 1930; KRÖLl 1968; SCHEMANN 1982; SCHMIDTRADEFElt 1993; WelKer 1990; FranCo 1991; Johnen 1997; RAmos 2000; Vilela; Koch 2001; Traugott 2007; Waltereit 2007; AQuino 2012; 2017; 2018; DiEWALD 2013; Fischer; Alm 2013; ARANTES 2017; 2019). Os teóricos citados assumem a existência de PMs nas línguas como o catalão, croata, francês, inglês e português, abrindo espaço para abordagens inclusivas e análises situadas em contextos. Essas abordagens certamente apresentam tendências importantes e têm sido destaque na literatura, sobretudo porque propõem classificação desses elementos modalizadores em outras línguas e comprovam sua existência.

Ainda que seja possível encontrar equivalentes em outras línguas, as características descritivas e as categorias gramaticais são distintas em alemão (AQUINO, 2017: 158-159) e podem apresentar equivalentes paraverbais em português brasileiro, tais como gestos, entonação e prosódia (ARANTES 2019: 178). Nesse sentido, temos a intenção de evidenciar que a língua portuguesa apresenta elementos modais que oferecem equivalentes funcionais relevantes para as PMs alemãs. Além disso, com base em pesquisas já realizadas em língua portuguesa, ambicionamos uma adequação da classificação destes elementos modais, que chamamos de PMs portuguesas (doravante PMpt). 
AQUINO, M. C.; ARANTES, P. C. C. - Partículas modais em alemão e seus equivalentes funcionais

Entendemos PMs como marcadores de funções pertencentes aos domínios da coesão social e interpessoal (relação ouvinte-falante, identidade social, tipo de ato social realizado), por isso o contexto das situações comunicativas em que elas aparecem é tão relevante para seu entendimento (ARANTES 2017; 2019). Se inferidas a partir de um contexto recuperável, as PMs funcionam como ferramentas gerando implicaturas fortes com a redução do esforço despendido para alcançar grandes efeitos contextuais (AQUiNo 2017: 67). Nos termos relevantistas (SPERBER; WILSON 2005: 221) elas são consideradas como procedurais, ou seja, itens que colocam restrições na interpretação do enunciado a serem processadas, a fim de coconstruir uma representação mental coerente do discurso.

As PMs tornam possível negociar inferências entre os interlocutores, ou seja, possibilitam reconhecer a atitude e intenção do falante e as expectativas do ouvinte. Nesse sentido, a negociação de informações relevantes para a comunicação funciona como avisos metapragmáticos (KÖNIG 1997: 60). Portanto, a necessidade de funções modais em outras línguas pode ser postulada pela simples suposição sobre a natureza da comunicação humana (WALTEREIT 2001: 1399-1400), isto é, a necessidade de meios linguísticos para acessar informações contextuais e compreensão de implicaturas.

Novas vias para a compreensão do comportamento sintático e a contribuição semântica das PMs foram recentemente pavimentadas por uma série de estudos que ligam a modalidade, em suas diversas manifestações, ao desenvolvimento da Teoria da Mente (ToM) (ABRAHAM; LEISS 2012; ABRAHAM 2012; LEISS 2012; MACHÉ 2012, entre outros), em que os falantes ganham acesso às representações mentais dos outros. Essa linha de raciocínio tem uma implicação óbvia em termos de aquisição de linguagem: enquanto as próprias representações mentais são diretamente acessíveis à consciência, as representações mentais de interlocutores de outras línguas e culturas são mais difíceis de inferir (FEDRIANI; SANSO 2017: 8-9).

Em alemão, as PMs representam uma classe gramatical aparentemente homogênea, com distintas características sintáticas, semânticas e pragmáticas, que foram desenvolvidas diacronicamente, apresentando um status topológico restrito (ABRAHAM, 1991: 231). Assim, sabemos que é preciso ter cuidado ao assumir a existência de uma mesma categoria com a mesma definição das PMs em outros idiomas. Não obstante, investigações atuais sobre o uso modal em diversas línguas, como os estudos do português 
AQUINO, M. C.; ARANTES, P. C. C. - Partículas modais em alemão e seus equivalentes funcionais

citados anteriormente, oferecem perspectivas relevantes para encontrar equivalentes funcionais desses elementos.

Logo, temos a intenção, neste artigo, de levantar literatura na área de pesquisa de PMs em outras línguas - catalão, croata, francês, inglês e português - com o intuito de estabelecer uma base teórica para a categorização de uma classe de palavras de PMs no português brasileiro. Além disso, realizamos uma análise inicial sobre os equivalentes funcionais em português das PMs alemãs, tendo como base as análises apresentadas nos trabalhos selecionados. Vale ressaltar que essa proposta é muito relevante para o ensino de língua alemã e língua portuguesa, sobretudo porque as PMs estão muito presentes na linguagem oral e auxiliam na argumentação.

\section{Partículas modais alemãs: uma breve revisão}

De forma geral, as PMs em língua alemã ${ }^{3}$ são classificadas como palavras que não sofrem flexão, englobando elementos normalmente caracterizados como advérbios, conjunções e preposições (HELBIG; BUSCHA 2002; DUDEN 2016). Além de não flexionáveis, as PMs apresentam outras características delimitadoras (cf. AQUINO 2020):

1. não são acentuadas;

2. não podem ser negadas ou intensificadas;

3. não respondem perguntas (

4. podem ser combinadas com outras PMs;

5. não formam um enunciado sozinhas;

6. apresentam função nuclear específica;

7. estão sintaticamente e gramaticalmente integradas na sentença;

8. são posicionadas no campo central da oração (Mittelfeld);

9. ocorrem em tipos específicos de sentenças;

10. têm escopo sobre toda a sentença;

11. são usadas especialmente em fala coloquial, mas não exclusivamente;

12. apresentam homônimos não modais em outras categorias;

13. têm sentido inferencial.

\footnotetext{
${ }^{3}$ As 15 PMs mais frequentes : aber, auch, bloß, denn, doch, eben, eigentlich, etwa, halt, ja, mal, nur, schon, vielleicht, wohl (HELBIG; BUSCHA 2002: 421; DUDEN, 2016: 602).

Pandaemonium, São Paulo, v. 23, n. 40, maio-ago. 2020, p. 166-190
} 
AQUINO, M. C.; ARANTES, P. C. C. - Partículas modais em alemão e seus equivalentes funcionais

Ainda, esses elementos modais atribuem o máximo de informação com menor esforço cognitivo; especificam a relação entre falante e ouvinte (AQUINO 2018: 269); referem-se a um acontecimento anterior à proposição que pode ser recuperado contextualmente (DIEWALD 2006: 406); indicam significados emocionais e afetivos (DEgand; Cornillie; Pietrandrea 2013: 14-15). Diewald (2013: 22) afirma que as PMs são modos convenientes e sutis de introduzir implicações, suposições e alusão de maneira implícita, e que este potencial é a razão da riqueza das funções comunicativas e retóricas desses elementos. Para Welker (1990:30), questões sociais sobre as particularidades do interlocutor (status, idade, sexo) também podem influenciar a escolha de uma PM.

A difícil classificação das PMs, portanto, pode advir (pelo menos em parte) de sua origem, isto é, a existência de homônimos não modais como advérbios, adjuntos, partículas escalares e adversativas e interjeições (ABRAHAM 1991:332). As PMs apresentam características diferentes dos lexemas que resultam de um processo de gramaticalização, tendo aspectos semânticos, sintáticos e pragmáticos distintos. Essas características foram desenvolvidas diacronicamente e apresentam um status tipológico restrito. Segundo Abraham (1991), as PMs derivam de elementos lexicais através da perda de complexidade semântica, mas ganho de complexidade pragmática. $\mathrm{O}$ autor defende ainda que a ocorrência das PMs é limitada a poucas línguas, como no alemão, e o motivo seria a sintaxe peculiar deste idioma. No entanto, Haan (2006), Arantes (2017; 2019), Johnen (1997), Aquino (2012; 2020) e diversos outros teóricos argumentam que, mesmo com uma estrutura sintática diferente do alemão, o português brasileiro também possui PMs.

Nesse sentido, as partículas são recursos retóricos da linguagem cotidiana para tornar mais específico um ato linguístico. Com elas, o falante acentua a intenção contida em seu enunciado, estabelece estratégias, implica explicação, justificação e repreensão e atua ainda na construção de pressupostos (ARANTES 2019). Além de revelar a atitude e o lado emocional do falante perante o enunciado produzido, as PMs podem também ser usadas com a intenção de influenciar a reação do ouvinte. Portanto, essas palavras apresentam uma função comunicativa tão relevante que, por meio delas, podemos modificar e até mesmo criar situações (AQUINO 2012: 12).

Logo, os usos modais podem ser considerados como ajustadores contextuais, tendo a função de verificar que os interlocutores estão entendendo uns aos outros (VASKó; 
AQUINO, M. C.; ARANTES, P. C. C. - Partículas modais em alemão e seus equivalentes funcionais

FRETHEIM 1997: 235), destacando aquilo que merece atenção. Segundo a ToM, essa habilidade linguística de identificar as informações conhecidas entre os interlocutores e acessar o ambiente cognitivo é chamada de deslocamento duplo (ABRAHAM; LEISS 2012: 11). De acordo com os postulados dessa teoria, os falantes abrem espaço para que os ouvintes avaliem o sucesso da enunciação realizada, negociando o significado, produzindo sentidos. Assim, tanto o conceito de deslocamento duplo, como o de metarrepresentação de Gutt (2005: 80), configuram uma compreensão complexa do discurso.

Ainda nesse sentido, as PMs são conhecidas por operar acima do nível proposicional, ou seja, elas têm a capacidade de organizar o discurso transmitindo informações sobre a característica epistêmica dos participantes do discurso (SCHENNER; SODE 2014: 296). Consequentemente, as partículas são meios retóricos para comunicar uma mensagem eficiente e concreta entre os indivíduos envolvidos no processo interpretativo. Portanto, as PMs se destacam por serem elementos complexos com um status ilocutório único, com um grande impacto gramatical (ABRAHAM; LEISS 2012: 8) e discursivo.

Segundo Köller (2004: 534), o fato de a língua alemã conter uma riqueza aparentemente maior de PMs do que outras línguas deve-se, provavelmente, à possibilidade de a modalização ser concretizada, em outras línguas, de outras maneiras, por meio de elementos paratextuais, tais como gestos, mímicas, entonação e prosódia. No entanto, estudos mostram que outras línguas, inclusive românicas, são também ricas em PMs, mas supomos que a razão para a invisibilidade das partículas no português brasileiro, por exemplo, deva-se ao fato de não terem sido ainda extensivamente classificadas (ARANTES 2019). No português brasileiro, por exemplo, temos uma tradição prescritiva de gramática, que pouco se interessa por ampliar seu horizonte classificatório para análises funcionais da língua, sobretudo para análises contextuais que dependeriam do discurso. Parece-nos que esse é o principal motivo para essa classe de palavras estar fora de nossas gramáticas normativas.

No estudo realizado por Arantes (2019), encontramos levantamento histórico da problematização das PMs em estudos românicos, observando-se que elementos modais têm sido classificados nas gramáticas, segundo Franco (1990), ora como advérbios, ora como interjeições. 
AQUINO, M. C.; ARANTES, P. C. C. - Partículas modais em alemão e seus equivalentes funcionais

No presente estudo propomo-nos a investigar o significado das PMs e seus equivalentes funcionais em português, assumindo uma abordagem minimalista, isto é, considerando que cada PM tem uma função nuclear que modifica a sentença, expressando diferentes graus de intensidade ao conteúdo enunciativo como um todo (DIEWALD 2007: 118). Weydt (1969: 68) afirma que as PMs possuem funções específicas e que compartilham a função principal de caracterizar a atitude do falante perante o enunciado. Assim, além das inferências contextuais é preciso conhecer a função nuclear específica de cada PM.

A PM doch, por exemplo, tem a função principal de indicar contradição a respeito de alguma situação ou informação. Já a PM wohl apresenta a função de sinalizar uma hipótese ou falta de comprometimento com alguma informação. A PM aber expressa uma exclamação, surpresa e conselho/encorajamento. Esses exemplos nos levam a considerar que seja interessante explorar as funções nucleares das PMs como ponto de partida para analisar, num segundo momento, o uso e sua aplicação para o ensino.

\section{Partículas modais em perspectiva contrastiva}

A questão sobre os equivalentes funcionais para as PMs é abordada há muito tempo em estudos de teoria de tradução, começando com o trabalho seminal de Weydt (1969). Não obstante, nos últimos anos tem-se dado especial atenção à investigação sobre a existência de PMs em línguas que, incialmente, eram consideradas sem a possibilidade de apresentar essa classe de palavras. Mesmo com a constante divergência na área, os trabalhos parecem concordar que, embora exista uma evidente diferença de classificação, é difícil conceber que as funções comunicativas das PMs sejam restritas a línguas particulares (WALTEREIT 2001: 1391). Nesta seção temos o intuito de apresentar os trabalhos seminais que abordam de maneiras distintas o estudo desses elementos modais em outras línguas, focando-nos principalmente nos aspectos pragmáticos, cognitivos e topológicos.

3.1 Partículas modais e seus equivalentes funcionais: abordagem teórica dos atos de fala Waltereit (2001) defende que as línguas românicas possuem uma classe de palavras de PMs, mesmo que em menor quantidade de ocorrência ao se comparar com o alemão. O autor afirma ainda que esses elementos em outros idiomas são igualmente relevantes, já 
AQUINO, M. C.; ARANTES, P. C. C. - Partículas modais em alemão e seus equivalentes funcionais

que também apresentam meios para expressar funções modais, que consistem essencialmente em expressar um ato de fala com uma despesa linguística mínima. Nesse sentido, existem diversos meios para expressar a modalidade, como a PM quando même em francês, o diminutivo em italiano, espanhol e português, e o backchecking em inglês (What was your name? or Who got the wine?) (WALTEREIT 2001: 1391).

O teórico apresenta o caso da PM but em inglês, que indica que alguma situação (state of affairs) apresenta-se como contrária às suposições implícitas contextualizadas. O equivalente funcional da PM but, segundo ele, seria a PM alemã ja, pois ambas são utilizadas em asserções para sinalizar que o falante presume que uma forte evidência do conteúdo proposicional do enunciado está disponível (KÖNIG 1997: 70). Além disso, tanto a PM but, como a PM ja em alemão são tipicamente associadas com o seu homônimo não modal (WALTEREIT 2001: 1404). A evidência que estas PMs sinalizam pode estar disponível através do conhecimento prévio do ouvinte ou de forma perceptual, como vemos a seguir:

(1) Dein Mantel ist ja ganz schmutzig! (KöNIG 1997: 70)

But your coat is all dirty! ${ }^{4}$

Quando o falante presume que há evidências fortes para a compreensão da situação, ele supõe que o ouvinte concorda com o conteúdo proposicional do enunciado. Se as implicações contextuais forem reconhecidas, as PMs funcionam como ferramentas comunicativas relevantes para a comunicação.

Waltereit (2001: 1414-1415) conclui que existem formas em outras línguas que realizam uma função análoga às PMs, cujo propósito seria o de apresentar informações relevantes em condições linguísticas mínimas. Ele afirma ainda que estes elementos surgem através da mudança semântica metonímica de suas contrapartes não modais, como é o caso de but e ja e, a nosso ver, assim como Franco (1991: 335-348), mas em português, como proporemos na seção 4, referente às análises dos correspondentes modais em língua portuguesa.

\footnotetext{
${ }^{4}$ Mas o seu casaco está sujo!

Pandaemonium, São Paulo, v. 23, n. 40, maio-ago. 2020, p. 166-190
} 
AquinO, M. C.; ARANTES, P. C. C. - Partículas modais em alemão e seus equivalentes funcionais

3.2 Partículas modais e marcadores discursivos sob ponto de vista diacrônico

Waltereit e Detges (2007) comparam o marcador bien em espanhol e a PM bien em francês, mostrando que a diferença funcional entre marcadores discursivos e PM podem ser averiguadas em termos diacrônicos. Eis os exemplos analisados pelos teóricos:

(2) Vous avez bien reçu mon message?

You have bien received my message? - You did receive my message, didn't you ${ }^{5}$

Nesses exemplos, a PM bien codifica as suposições do falante sobre a atitude do ouvinte perante a validade de uma asserção. Desse modo, o falante espera que a resposta do ouvinte seja afirmativa, negociando assim um conhecimento comum entre eles (Waltereit; Detges 2007:77). No entanto, o estudo de Waltereit e Detges não apresenta uma investigação aprofundada sobre as funções modais da PM bien ou sua correspondência no alemão, mas destaca as mudanças diacrônicas para a formação das duas classes de palavras no francês e espanhol.

3.3 Problemas para definir a categoria de partículas modais

Schoonjans (2013) discorre, basicamente, sobre a descrição da categoria de PMs, questionando a existência desses elementos em outras línguas e a possibilidade de haver elementos similares às ocorrências no alemão. $\mathrm{O}$ autor defende que é necessária uma análise descritiva relacionando as PMs com outras categorias, como advérbios e conjunções na mesma língua, e uma investigação de como elas corresponderiam ao alemão. Sua análise é ilustrada contrastivamente pelas PMs em inglês e em francês, como nos exemplos abaixo (SCHOONJANS, 2013: 44-45):

(3) Mais je ne peux tout de même pas les faire coincer?

But I can't tout de même make them get caught?

(4) Asseyez-vous donc, Messieurs!

Take donc a seat, gentlemen!

\footnotetext{
${ }^{5}$ Você bem que recebeu a minha mensagem né?

Pandaemonium, São Paulo, v. 23, n. 40, maio-ago. 2020, p. 166-190
} 
AQUINO, M. C.; ARANTES, P. C. C. - Partículas modais em alemão e seus equivalentes funcionais

(5) Si j'avais seulement pu le consulter avant de rencontrer Reslaut!

'If seulement I could have consulted him before meeting Reslaut!

O teórico observa que as PMs em alemão e em francês não podem ser conjugadas, negadas ou acentuadas; não apresentam um valor constituinte e têm escopo sobre a frase toda. Contrastivamente, as funções dos exemplos 3 e 4 em francês correspondem à PM doch em alemão, e bloß ou doch nur no exemplo 5. Além disso, o autor evidencia que as PMs francesas são posicionadas entre os verbos finitos e infinitos, ou seja, no campo central (Mittelfeld), estando de acordo com as regras topológicas das PMs em alemão (SCHOONJANS 2013: 145).

Ainda assim, estudiosos como Abraham (1991) afirmam que o francês não pode ter PMs por razões topológicas, já que as PMs em alemão são restritas ao campo central, enquanto línguas românicas não possuem a mesma divisão de campos. No entanto, Schoonjans argumenta que existem PMs em alemão, como halt, que na linguagem falada podem ocorrer fora do campo central. De fato, tanto o francês como o português não apresentam a mesma categoria de PMs do alemão, mas possuem uma classe de palavras correspondente que manifesta a mesma característica intencional (ScHOONJANS 2013: 145-146).

A afirmação do autor parece encontrar suporte em trabalhos como o de Söll (1974) e Mosegaard (1998), entre outros que defendem a existência de PMs na língua francesa. Assim, a existência da categoria das PMs em outras línguas não necessariamente implica cenários completamente comparáveis com o do alemão, mas sim a existência de classes de palavras que exprimem semelhantes intenções comunicativas.

Schoonjans conclui que em francês existe uma categoria de PMs que possui uma estrutura prototípica (na maioria dos casos, no campo central) e fuzzy boundaries que acabam sobrepondo-se a outras categorias como advérbios e marcadores discursivos, assim como a contrapartida em alemão. Como em francês, outras línguas apresentariam, segundo ele, situações similares, ou seja, uma categoria de PMs que fortemente se assemelham às do alemão; e para essa definição, características prototípicas e conceituais podem ser úteis (SCHOONJANS 2013: 150-151).

Pandaemonium, São Paulo, v. 23, n. 40, maio-ago. 2020, p. 166-190 
AQUINO, M. C.; ARANTES, P. C. C. - Partículas modais em alemão e seus equivalentes funcionais

3.4 Limites difusos entre marcadores discursivos e marcadores modais

Cuenca (2013) apresenta uma análise baseada em corpus oral (COC, Corpus oral de conversa colloquial, PAYRATO; ALtURO 2002), constituído da conversa espontânea de três participantes. A análise da PM é focada em es que do catalão:

(6) Bueno es que la mare es de jutjat eh (COC04: 1506-1509)

Well, es que '(it) is just that' his mother is very difficult to deal with.

Como observamos nos exemplos, es que possui a função de justificar a asserção, ou seja, apresentar o motivo pelo qual os personagens não se dão bem, excluindo-se outras hipóteses ou inferências contrárias que poderiam ser feitas. Com o uso dessa PM pressupõe-se o conhecimento de contexto ou informação anterior, além da expectativa de uma resposta ou uma reação a esse conhecimento. A autora afirma, ainda, que es que ocorre comumente no discurso oral e tem valor modal ao relacionar a intenção do falante de justificar o seu comportamento a fim de evitar discórdia.

Cuenca conclui, portanto, que es que como PM introduz uma situação objetiva e pressupõe um conteúdo pré-existente, implícito ou explícito, em que a sentença (com PM) é uma justificativa ou desculpa. Assim como a maioria das partículas em alemão, esta PM tem escopo sobre toda a sentença e modifica o valor ilocucionário. Essa análise se assemelha à de Franco (1991: 319-324), que sugere o uso de é que como PM para o português de Portugal, como no exemplo apresentado pelo autor, "O José é que comprou o carro". Na seção 4.3 abordaremos exemplos de é que para o português brasileiro.

3.5 Marcadores discursivos e partículas modais: funções do then em inglês falado

Segundo Haselow (2011), then final é um fenômeno topológico raro, já que os advérbios conectores aparecem normalmente no início ou no meio da oração. No início, o advérbio marca a conexão textual, facilitando a intepretação da relação semântica da nova unidade, ao passo que, utilizado no final, requer um processo de reinterpretação do enunciado, pois modificaria a força ilocucionária deste. Nesse sentido, then final é utilizado para indicar uma relação de contraste entre um estado de coisas esperado e o real. 
AQUINO, M. C.; ARANTES, P. C. C. - Partículas modais em alemão e seus equivalentes funcionais

O teórico defende que then final pertenceria à classe de palavras das PM e teria a função principal de expressar surpresa ou impaciência. Em contraste com outras posições, a PM then seria utilizada para regular a relação entre os participantes e para estruturar a fala. Assim, ela não opera apenas no nível textual, criando coesão entre unidade do discurso, mas é usada para ligar um discurso a uma proposição não verbal implícita. Vejamos os exemplos retirados do artigo (HASELOW 2011: 3605-3610):

(7) A: do you actually quote any of the actual figures?

E: yeah uh I think so.

A: read it then.

(8) B: uhm I'll have a vodka and lemonade if you've got any.

Z: well have vodka and lime then.

As PMs, assim como then final em inglês, condicionam uma função metalinguística, isto é, se referem a aspectos da atitude do falante em relação ao conteúdo de uma informação e modificam a força ilocutória da mensagem. A PM then também é usada no nível interpessoal, na relação entre interlocutores e com o objetivo de trazer mais suavidade, ou demonstrando falta de compreensão com o comportamento do interlocutor (HASELOW 2011: 3611):

(9) Nimm doch etwas Wodka

Have a Wodka then.

(10) Du musst mir ja zuhören!

You have to listen to me then!

Then como PM expressa uma relação contrastiva entre um estado de coisas suposto e a realidade, indicando surpresa, interesse, discordância, atitude pessoal do falante, além de modificar a força ilocutiva do enunciado, abrindo uma lacuna conversacional para o ouvinte. O contexto pragmático deve estar baseado em suposições, expectativa sobre um conhecimento específico ou geral que pode ser inferido (From what I know about the current situation, I consider it as given that I ask: proposition P). No 
AQUINO, M. C.; ARANTES, P. C. C. - Partículas modais em alemão e seus equivalentes funcionais

próximo exemplo podemos observar a função da PM de contraste ou quebra de expectativa (HASELOW 2011: 3613):

(11) So what did you do today?

(12) So what do you do today then?

Then final cria uma relação com o pretexto pragmático, além de ter escopo na oração toda. Ainda segundo Haselow, a PM then é mais "amigável”, pois envolve o ouvinte na negociação, trabalha no nível interpessoal, indicando o tipo de relação entre interlocutores (formal ou menos formal). $\mathrm{O}$ autor conclui que a diferença principal entre as PMs no alemão e em inglês seriam as propriedades sintáticas, isto é, o posicionamento no Mittelfeld. No entanto, existem mais semelhanças que diferenças, como a restrição de tipos ilocucionários (perguntas e diretivas); escopo restrito; função comunicativa modal; dependência e ligação com pretextos pragmáticos; relevância da relação entre os interlocutores.

\subsection{Descrição de PMs Alemãs e seus equivalentes funcionais em croata e inglês}

Ao analisar as contrapartes das PMs alemãs e croatas, o estudo de Kresić, Angster e Diewald (2017) propõe um método para a descrição lexicográfica da função discursiva das PMs, englobando os níveis morfológico, sintático, semântico e pragmático. Segundo as autoras, o croata apresenta uma classe de expressões que cumprem as mesmas funções que as PMs em alemão, como podemos constatar no exemplo retirado do estudo (KRESIĆ; ANGSTER; DIEWALD 2017: 233):

(13) Wie heißt er gleich?

Kako se on ono zove?

What was his name again? (= adverb + simple past tense)

Ao contrário do alemão, essa classe de expressões em croata apresenta maior variabilidade na distribuição sintática. Com base na análise contrastiva proposta, que também leva em conta o inglês (idioma sem PM, segundo a perspectiva das autoras), seria 
AQUINO, M. C.; ARANTES, P. C. C. - Partículas modais em alemão e seus equivalentes funcionais

possível encontrar uma descrição de PMs e seus equivalentes funcionais em todos os idiomas.

As teóricas definem uma categoria de PMs em croata baseando-se na função pragmática das PMs, isto é, função gramatical específica do discurso que consiste na ancoragem do enunciado em uma configuração dialógica (DIEWALD 2013, DIEWALD et al. 2009). A função dialógica comum, bem como as funções distintivas específicas foram descritas com a ajuda de um formato para a descrição das PMs em uma perspectiva intralinguística, que foi desenvolvida por meio de análises de corpus falado e escrito, em alemão, croata e inglês (KRESIĆ; ANGSTER; DIEWALD 2017: 233).

Parte-se, ainda, do pressuposto de que cada PM teria uma função nuclear determinada pela forma como conecta o enunciado ao contexto, e de que ela teria escopo na frase, apresentando, desse modo, funções equivalentes em vários idiomas. As suposições centrais do estudo focam na premissa de que as palavras da categoria de PMs em alemão e croata compartilham a maioria dos recursos formais, mas diferem na forma.

No entanto, esses meios linguísticos compartilham a mesma função pragmática de marcar a ancoragem dialógica do enunciado. Nesse sentido, essa função pode ser realizada em outras línguas por vários meios formais, que vão desde itens gramaticais de classe fechada, como as PMs, ou construções menos gramaticalizadas, como tagquestions em inglês, e recursos não segmentáveis, como entonação (KRESIĆ; ANGSTER; DIEWALD 2017: 236).

\section{Proposta de descrição das partículas modais brasileiras e seus equivalentes funcionais: análise e discussão}

Como vimos, PMs são classes de palavras altamente específicas de uma língua (WALTEREIT; DETGES 2007) e precisam ser analisadas de acordo com o contexto em que são enunciadas. Assim, desenvolvemos nesta seção uma análise das PMpt, refletindo sobre o seu uso, significado e os equivalentes funcionais em português. Para isso temos como base as análises das PMs discutidas na revisão teórica deste artigo, sendo elas: but (Waltereit 2001), bien (Waltereit; Detges 2007), es que (CUENCA 2013) e then (HASElOW 2011). Além de introduzir as interpretações destas PMs com as PMpt, sugerimos os equivalentes em alemão, já que tomamos como base as análises e classificações desses elementos modais em língua alemã.

Pandaemonium, São Paulo, v. 23, n. 40, maio-ago. 2020, p. 166-190 
AQUINO, M. C.; ARANTES, P. C. C. - Partículas modais em alemão e seus equivalentes funcionais

Partindo da premissa de que as PMs só podem ser traduzidas no contexto de um enunciado, consideramos que fornecer glosas individuais não é recomendável, uma vez que não há correspondências lexemáticas para essa categoria de palavras em diferentes línguas. Nesse sentido, avaliamos criticamente gramáticas e livros didáticos de aprendizagem de alemão como língua estrangeira (ALE) que oferecem listas de significados ou explicações simplificadas, não sendo eficientes para o ensino do caráter multifuncional que as partículas englobam (ARANTES 2017: 123).

Desse modo, discutiremos as propostas de tradução e equivalentes funcionais das PMs, procurando recuperar, sempre que possível, seu contexto de realização e sua função comunicativa específica. Ressaltamos que, em alguns casos, a recuperação do contexto não foi possível, por não haver descrição detalhada nos exemplos analisados nas obras dos autores selecionados. Quando isso acontecer, buscaremos supor alguns contextos, apresentando possíveis alternativas enquanto falantes do português brasileiro.

\section{1 ja, aber, but, mas}

A função modal de ja é descrita em praticamente todas as grandes gramáticas de língua alemã, e sua classificação é diferente daquela de seu homônimo não modal (advérbio de afirmação). Em português, propomos mas como equivalente funcional para $j a$, em alemão. Alguns estudos (Franco 1991; SCHMIDT-RADEFELDT 1993; VILELA; KocH 2001) reconhecem que mas, dependendo do seu uso, pode apresentar um caráter modal em português, diferenciando-o de seu homônimo (conector adversativo). No entanto, não encontramos essa classificação em gramáticas normativas do português.

A classificação das denominadas partículas modais nos manuais e gramáticas de língua portuguesa é bastante controversa e ainda não há consenso sobre o espaço que elas deveriam ocupar nesses suportes, bem como sobre sua classificação. (ARANTES 2017: 129)

Parece-nos que essa dificuldade em reconhecer o caráter modal de alguns termos em português deve-se à necessidade de buscar uma classificação teórica que confronte as descrições que as gramáticas tradicionais e normativas do português têm apresentado. É preciso, portanto, investir em um quadro de descrição pragmática das línguas falada e escrita, das investigações em análise do discurso para que se reconheça as PMpt, especialmente no contexto brasileiro.

Segundo Vilela (1999: 263), há no português "partículas modais típicas", as quais se referem ao conteúdo frásico total, "transportando um juízo de valor por parte do 
AQUINO, M. C.; ARANTES, P. C. C. - Partículas modais em alemão e seus equivalentes funcionais

enunciador" ou se limitando a certas sequências importantes da frase. Para o autor, mas é um candidato a integrar essa categoria, exprimindo "espanto", "surpresa".

A partir das análises dos exemplos de Waltereit (2001), sugerimos a interpretação das PMs ja e but para o português da seguinte forma:

(14) Alemão: Dein Mantel ist ja ganz schmutzig!

Inglês: But your coat is all dirty!

Português: Mas o seu casaco está todo sujo!

Nesse caso, vamos além da sugestão de Vilela (1999) para compreender a função de mas que não está restrita à expressão de surpresa ou espanto com o que está sendo enunciado, mas também para antecipar um conteúdo proposicional que os interlocutores compartilham. Imaginemos uma situação em que alguém veste o seu casaco sujo em casa e, à porta, alguém lhe diz: “mas o seu casaco está todo sujo!”.

Parece-nos que o interlocutor não apenas expressa surpresa com o fato de a pessoa intencionar sair com o casaco sujo, como também ressalta que essa informação é compartilhada entre eles: você sabe que o casaco está sujo e, mesmo assim, está querendo sair com ele. Vemos que o conteúdo adversativo está implícito na proposição não enunciada: "sair com o casaco", mas que pode ser presumida, sobretudo no momento em que alguém veste um casaco e se aproxima da porta.

Da mesma maneira, poderíamos assumir que em língua portuguesa também temos o uso modal da PMpt mas, como na tradução desses exemplos. O fato de o casaco estar sujo é conhecido; no entanto, com o uso das PMs é possível trazer pistas contextuais, por exemplo: os interlocutores sabem que o casaco está sujo, mas não sabiam que estava tão sujo, e quando estão prestes a sair de casa, percebem que é necessário trocar a peça, já que ela está mais suja do que se imaginava.

Portanto, para a interpretação do conteúdo enunciativo como PM é essencial o conhecimento da função nuclear das PM, assim como a análise do contexto e das intenções comunicativas entre os interlocutores (AQUINO 2017: 174).

Em alemão o uso de aber como PM, assim como a PMpt mas, indica quebra de expectativa ou surpresa:

Pandaemonium, São Paulo, v. 23, n. 40, maio-ago. 2020, p. 166-190 
AQUINO, M. C.; ARANTES, P. C. C. - Partículas modais em alemão e seus equivalentes funcionais

(15) Alemão: Das Wasser ist aber warm!

Português: Mas que água quente!

Inglês: $B u t$ the water is warm!

(16) Alemão: Das ist aber ein Auto!

Português: Mas isso sim é um carro!

Inglês: That is but a car!

Em Hentschel e Weydt (2013) encontramos uma pista para diferenciar o uso das PMs ja e aber em alemão, pois elas parecem apresentar sentidos muito semelhantes. Segundo os autores, as duas PMs expressam surpresa, a diferença está no tipo/motivo dessa reação. Em “Der Kaffee ist ja heiß!” a PM ja expressa surpresa que o café esteja quente, pois esperava-se que ele estivesse morno, ao ponto de beber. Ao contrário, em "Der Kaffee ist aber heiß!” a PM aber demonstra surpresa que o café esteja mais quente do que o esperado, ou seja, era esperado que o café estivesse quente, mas não tanto. Assim, ja sinaliza surpresa de algo inesperado (was/what), e aber indica surpresa com relação à extensão dos fatos (wie/how). A PM aber, portanto, exprime surpresa/espanto/admiração com relação à extensão quantitativa. Supõe-se que o conteúdo da sentença, nesses casos, seja conhecido de ambos os interlocutores. Nos dois casos, pode-se observar semelhança com o uso da PMpt mas.

\section{2 wohl, bien e bem (que)}

Como vimos em Waltereit e Detges (2007), a PM francesa bien codifica as suposições do falante sobre a atitude do ouvinte perante a validade de uma asserção. Fazendo um levantamento sobre as PMs no português brasileiro, chegamos à conclusão de que o correspondente bem (que) é um equivalente para os enunciados em francês e em inglês apresentados pelos autores e em alemão, como podemos observar nestes exemplos:

(17) Alemão: Du hast wohl meine Nachricht bekommen.

Francês: Vous avez bien reçu mon message?

Inglês: You did receive my message, didn't you?

Português: Você bem (que) recebeu a minha mensagem, né?

Pandaemonium, São Paulo, v. 23, n. 40, maio-ago. 2020, p. 166-190 
AQUINO, M. C.; ARANTES, P. C. C. - Partículas modais em alemão e seus equivalentes funcionais

Nas gramáticas normativas da língua portuguesa é possível encontrar apenas a classificação de bem como advérbio de modo, faltando uma adequação para bem (que) com função modal. Em Cunha e Cintra (2008), encontramos a classificação de é que como locução denotativa de realce e, desse modo, os autores afirmam que "tais palavras não devem ser incluídas entre os advérbios", pois "não modificam o verbo, nem o adjetivo, nem outro advérbio. São por vezes de classificação extremamente difícil" (CUNHA; CINTRA 2008: 567). Schmidt-Radefeldt (1993: 66) considera em sua análise a locução $e ́$ que como PMpt, que, segundo o teórico, é utilizada em atos de fala declarativos, "apresentando um facto bem conhecido dos interlocutores, e sobretudo quando se trata de um saber conhecido ou suposto como conhecido" (SCHMIDT-RADEFELDT 1993: 68).

Como o trabalho de Schmidt-Radefeldt tem o português de Portugal como base para sua comparação, entendemos que o uso de bem (que) no contexto exposto está mais apropriado ao português do Brasil. Percebe-se, portanto, que a frase possui a função ilocutiva de uma suposição ou conjectura, exprimida pelo falante como um saber suposto. Em contextos similares, a partícula alemã wohl parece apresentar funções comunicativas análogas às PMs em francês e português, pois modaliza a afirmação do enunciado, exprimindo um saber que é compartilhado pelos interlocutores. A PMpt bem (que) se estabelece pela necessidade de comparar/disputar a validade de uma asserção, e faz referência a uma contra expectativa forte por parte do ouvinte.

\section{$4.3 j$ j, es que e é que}

Como vimos, não é possível encontrar nas gramáticas normativas da língua portuguesa classificações das PMs. Essa dificuldade é expressa por Franco (1988), cujo artigo traz uma compilação de teóricos, que consideram tais palavras como "palavras ou locuções expletivas", usadas "quando, para darmos realce a um dos elementos da proposição, lhe juntamos certas palavras ou locuções desnecessárias ao sentido" (FRANCO 1988: 141). O autor apresenta o caso da PMpt é que, como em "Isto é que é felicidade!".

Em Martins (1899) já foi possível observar a classificação de que como partícula de realce a um dos elementos da proposição, sem especificar qual elemento seria realçado e qual posição ele deveria ocupar na frase. Embora Martins (1899: 57) sustente que que é utilizado como expressão de realce, "quando serve unicamente para reforçar uma 
AQUINO, M. C.; ARANTES, P. C. C. - Partículas modais em alemão e seus equivalentes funcionais

afirmação", o autor procura especificar que tais expressões serviriam para fazer sobressair o sujeito ou um complemento.

A locução é que foi, como vimos anteriormente, já considerada enquanto partícula modal nos estudos de Schmidt-Radefeldt (1993). Cuenca (2013) discute que o uso desta PM denota a pressuposição do conhecimento de contexto ou informação anteriores, além da expectativa de uma resposta ou reação a esse conhecimento.

Nesse sentido, sugerimos é que como equivalente funcional para a PM em catalão es que introduzida pelas autoras:

(18) Alemão: Es ist ja schwer mit seiner Mutter umzugehen.

Catalão: Bueno es que la mare es de jutjat eh.

Inglês: Well, es que '(it) is just that' his mother is very difficult to deal with.

Português: Bom, é que a mãe dele é difícil de lidar.

Nossa sugestão de tradução de es que como é que no português brasileiro também parece produzir efeito discursivo semelhante ao do uso em catalão, pois trata-se de uma justificativa ou desculpa que se pretende antecipar, mas que é conhecida dos interlocutores. No caso traduzido para o português "Bom, é que a mãe dele é difícil de lidar”, a partícula é que antecipa para o interlocutor que uma justificativa ou reforço da afirmação será apresentada. Além disso, a PM tem escopo sobre toda a sentença e modifica o valor ilocucionário, o que está de acordo com a classificação das PMs em alemão.

\section{4 doch, ja, then e então}

De acordo com a análise de Haselow (2011), o uso de then em posição final na frase exprimiria a função principal de surpresa ou impaciência. Segundo o autor, then expressaria uma relação contrastiva entre um estado de coisas suposto e a realidade, indicando surpresa, interesse, discordância, modificando a força ilocutiva do enunciado. Desse modo, o uso de then em outras posições sintáticas levaria a outras interpretações, mas seu uso no final da frase parece regular a relação entre os participantes, não operando 
AQUINO, M. C.; ARANTES, P. C. C. - Partículas modais em alemão e seus equivalentes funcionais

apenas no nível textual, mas conectando um discurso a uma proposição não verbal implícita.

A PMpt então poderia, a nosso ver, funcionar como correspondente de then em português, como podemos observar em nossa sugestão de interpretação:

(19) Alemão: Nimm doch etwas Wodka

Inglês: Have a Vodka then.

Português: Tome uma Vodka então.

(20) Alemão: Du musst mir ja zuhören!

Inglês: You have to listen to me then!

Português: Me escute então!

O estudo de Franco (1990) sobre as partículas PMpt considera que então pode ter função modal, necessitando de uma adequação de classificação. $\mathrm{O}$ teórico analisou apenas frases interrogativas iniciadas com então. No entanto, a função observada pelo teórico nos exemplos aproxima-se da função observada por Haselow (2011). Para Franco (1990), então exprimiria o interesse de quem interroga pela resposta à pergunta. Vê-se, portanto, que seu uso parece modificar a relação dos participantes e a força ilocutiva do enunciado, interpelando e provocando seu interlocutor a reagir, a responder.

Dessa maneira, então se aproximaria do sentido tanto das PMs doch e ja apresentadas como da PM denn, que expressa uma busca pela informação quando o contexto exprime motivo para tal. Então pode implicar contraste, justificar ou pedir justificativa, explicar e convencer. Além disso, essas PMs envolvem o ouvinte na negociação das informações relevantes no discurso, trabalhando no nível interpessoal e indicando o tipo de relação entre interlocutores.

\section{Conclusões}

Como vimos ao longo do presente artigo, as funções modais nos idiomas analisados são utilizadas e conceitualizadas de maneiras diferentes. A disposição sintática, por exemplo, 
AQUINO, M. C.; ARANTES, P. C. C. - Partículas modais em alemão e seus equivalentes funcionais

varia em todas as línguas analisadas, porém, no alemão parece existir uma maior estabilidade na classificação desses elementos modais (TRAUGOTT 2007: 142).

A língua portuguesa (assim como o catalão, croata, francês e inglês) não possui a mesma categoria de PMs em relação ao alemão, mas apresenta uma classe de palavras correspondente, com características intencionais equivalentes. A investigação da categoria de palavras modais em outras línguas não necessariamente implica uma correlação direta com as PMs de língua alemã, mas possibilita uma adequação na classificação e, portanto, a representação de uma classe de palavras definida nas gramáticas.

Defendemos a existência de uma classe de palavras de PMs em língua portuguesa, possuindo uma estrutura, regras de uso, funções nucleares e limites difusos com os seus homônimos não modais, se sobrepondo a outras categorias como advérbios e PMs, assim como a contrapartida em alemão. Nesse sentido, a descrição de regularidades das PMpt é um ponto muito importante para a reflexão acerca desta temática. Além da adequação das gramáticas, espera-se que esta análise sirva de base para a concepção de materiais de aprendizagem, tanto em ALE como em português (língua materna e estrangeira), que possam compreender uma variedade de exercícios situacionais contendo PMs e usos pragmáticos e modalizadores da língua.

Nosso objetivo foi, neste momento, oferecer caminhos para a descrição dos sentidos e efeitos discursivos produzidos pelas PMs, bem como comparar suas funções de modo interlinguístico. A recuperação dos efeitos produzidos pelas PMs, por meio das análises de seus equivalentes funcionais, pode ser um ponto de partida útil para análises comparativas e contrastivas de itens linguísticos similares em outros idiomas, sobretudo em aulas de língua estrangeira. Desse modo, refletimos sobre a relevância de abordar equivalentes funcionais das PMs alemãs em português, no sentido de fornecer um novo ponto de partida para comparações intralinguísticas e futuros estudos.

Concluímos que caminhos de gramaticalização similares que ligam domínios funcionais compatíveis podem ser encontrados por meio de seus equivalentes funcionais em outras línguas. Consequentemente, como perspectivas futuras, seria perspicaz investigar: (i) com base em Franco (1991), a relação entre os tipos de sentença e os significados das PMs, para explorar a relação entre a função de uma PM e sua fonte léxica; (ii) os padrões de gramaticalização em relação à função que assumem em tipo de frase 
AQUINO, M. C.; ARANTES, P. C. C. - Partículas modais em alemão e seus equivalentes funcionais

específica; (iii) a padronização da análise das PMpt, abordando sua função nuclear, características prototípicas.

Entendemos que classes linguísticas são específicas de um idioma, mas isso não quer dizer que comparações entre línguas (e potencialmente generalizações) por meio de equivalentes funcionais não possam ser feitas. Em outras palavras, defendemos a existência da categoria de PMs em outras línguas além do alemão, como o fizemos em português brasileiro. Demonstramos em nossa análise que é possível encontrar equivalentes funcionais relevantes e abrimos a discussão sobre a adequação de classificação desses elementos modais, abordando suas funções sintáticas, semânticas e pragmáticas.

\section{Referências Bibliográficas}

ABRAHAM, W. Discourse particles in German: how does their illocutive force come about? In: ABRAHAM, W. (ed.). Discourse particles: descriptive and theoretical investigations on the logical, syntactic, and pragmatic properties of discourse particles in German. Amsterdam: Benjamins, 1991, p. 203-252.

ABRAHAM, W. Sprecherdeixis und Merkmaldistributionsdifferential deutscher Modalitätselemente. Deutsche Sprache: Zeitschrift für Theorie, Praxis, Dokumentation, Berlin, v. 40, n. 1, 2012, p. 72-95.

ABRAHAM, W.; LEISS, E. (eds.) Modality and theory of mind elements across languages. Berlin: Mouton de Gruyter, 2012.

AQuino, M. A força comunicativa das partículas modais alemãs no ensino de línguas. Diálogo das Letras, Pau dos Ferros, v. 1, n. 2, 2012, p. 103-115.

AQuino, M. O questionário como ferramenta no ensino de partículas modais alemãs. Pandaemonium Germanicum, São Paulo, v. 20, n. 32, 2017, p. 156-179.

AQUINO, M. A tradução da partícula modal wohl para o português: uma investigação do esforço de processamento de participantes brasileiros e alemães. Revista Cadernos de Tradução, Florianópolis, v. 38, n. 3, 2018, p. 352-374.

AQUINO, M. C. O ensino das partículas modais alemãs: estratégias didáticas em ALE. Revista Brasileira de Linguística Aplicada, Belo Horizonte, 2020.

ARANTES, P. C. C. Análise pragmática do uso de partículas modais em alemão e em português: incentivo às abordagens metalinguísticas no ensino de alemão em contexto universitário. In: UPHOFF, D. et al. $O$ ensino de alemão em contexto universitário: modalidades, desafios e perspectivas. São Paulo: Humanitas, 2017, p. 123-144.

ARANTES, P. C. C. Eine pragmatische Gebrauchsanalyse der Modalpartikeln im deutschportugiesichen Vergleich. In: JOHNEN, T.; SAVEDRA, M.; SCHRÖDER, U. (org.). Sprachgebrauch im Kontext: die deutsche Sprache im Kontakt, Vergleich und in Interaktion mit Lateinamerika/Brasilien. Stuttgart: Ibidem-Verlag, 2019, p. 173-198.

CuEnCA, M. J. The fuzzy boundaries between discourse marking and modal marking. In: Degand, L.; Pietrandrea, P.; CoRnilie, B. (org.). Discourse markers and modal particles: categorization and description. Amsterdam: John Benjamins, 2013, p. 191-216. 
AQUINO, M. C.; ARANTES, P. C. C. - Partículas modais em alemão e seus equivalentes funcionais

CUNHA, C.; CINTRA, L. Nova gramática do português contemporâneo. Rio de Janeiro: Lexikon, 2008.

DIEWALD, G. Discourse particles and modal particles as grammatical elements. In: FISCHER, K. Approaches to discourse particles. Amsterdam: Elsevier, 2006, p. 403-426.

DIEWALD, G. Abtönungspartikel. In: HofFMANN, L. Handbuch der deutschen Wortarten. Berlin: De Gruyter, 2007, p. 117-141.

DIEWALD, G. Same same but different: modal particles, discourse markers and the art (and purpose) of categorization. In: Degand, L.; Pietrandrea, P.; Cornilie, B. (org.). Discourse markers and modal particles: categorization and description. Amsterdam: John Benjamins, 2013, p. 19-46.

Degand, L.; CoRnilie, B.; PIETRANDREA, P. Discourse markers and modal particles: two sides of the same coin? In: Degand, L.; Pietrandrea, P.; CoRnilie, B. (org.). Discourse markers and modal particles: categorization and description. Amsterdam: John Benjamins, 2013, p. 1-18.

DUDEN. Grammatik der deutschen Gegenwartssprache. Mannheim: Dudenverlag, 2006.

FEDRIANI, C.; SANSO, A. Pragmatic markers, discourse markers, and modal particles: what do we know and where do we go from here? Amsterdam: John Benjamins, 2017, p. 419-439.

FISCHER, K.; ALM, M. A radical construction grammar perspective on the modal particlediscourse particle distinction. In: Degand, L.; PietrandREA, P.; CorniLie, B. (org.). Discourse markers and modal particles: categorization and description. Amsterdam: John Benjamins, 2013, p. 47-88.

FRANCO, A. Partículas modais da língua portuguesa: relances contrastivos com as partículas alemãs. Revista da Faculdade de Letras do Porto Linguas e Literatura, Porto, II série, n. 5, 1988, p. 137-156.

FRANCO, A. Partículas modais do português. Revista da Faculdade de Letras do Porto Línguas e Literatura, Porto, II série, n. 7, 1990, p. 175-196.

FRANCO, A. Descrição linguística das partículas modais no português e no alemão. Coimbra: Coimbra Editora, 1991.

GUTT, E.-A. Challenges of metarepresentation to translation competence. In: FLEISCHMANN, E.; SCHMITT, P. A.; WOTJAK, G. (org.). Tagungsberichte der LICTRA (Leipzig International Conference on Translation Studies). Tübingen: Stauffenberg, 2005, p. 77-89.

HAAN, F. Typological approaches to modality. In: FRAWLEY, W. The expressiom of modality. Berlin: Mouton de Gruyter, 2006, p. 27-70.

HASELOW, A. Discourse marker and modal particle: the functions of utterance-final then in spoken english. Journal of Pragmatics, Amsterdam, v. 43, 2011, p. 3603-3623.

HeLbIG, G.; BusChA, J. Deutsche Grammatik. Leipzig: Verlag Enzyklopädie, 2002.

Hentschel, E.; Weydt, H. Handbuch der Deutschen Grammatik. 4. ed. Berlin: De Gruyter, 2013.

JoHnen, T. Aí como partícula modal do português. In: MotA, J. (org.). Atas do $1^{\circ}$ Congresso Internacional da Associação Brasileira de Lingüística. v. 2. Comunicações, disquete 6: Lexicologia e Semântica. Salvador: Instituto de Letras da Universidade Federal da Bahia, 1997.

KÖLLER, W. Perspektivität und Sprache: Zur Struktur von Objektivierungsformen in Bildern, im Denken und in der Sprache. Berlin: De Gruyter, 2004.

KÖNIG, E. Zur Bedeutung von Modalpartikeln im Deutschen: Ein Neuansatz im Rahmen der Relevanztheorie. Germanistische Linguistik, v. 136, 1997, p. 57-75.

Kresić, M.; ANGSTER, M. B.; Diewald, G. A format for the description of German modal particles and their functional equivalents in Croatian and English. In: FEDRIANI, C.; SANSO, A. Pragmatic markers, discourse markers, and modal particles: what do we know and where do we go from here? Amsterdam: John Benjamins, 2017, p. 229-254.

Pandaemonium, São Paulo, v. 23, n. 40, maio-ago. 2020, p. 166-190 
AQUINO, M. C.; ARANTES, P. C. C. - Partículas modais em alemão e seus equivalentes funcionais

KRÖLL, H. Die Ortsadverbien im Portugiesischen unter besonderer Berücksichtigung ihrer Verwendung in der modernen Umgangssprache: Mainzer Romanistische Arbeiten. Wiesbaden: Franz Steiner Verlag, 1968.

LEISS, E. Epistemicity, evidentiality, and Theory of Mind (ToM). In: ABRAHAM, W.; LEISS, E. (ed.). Modality and theory of mind: elements across languages. Berlin: De Gruyter, 2012. p. 37-66.

MACHÉ, J. Exploring the theory of mind interface. In: ABRAHAM, W.; LEISS, E. Modality and theory of mind elements across languages. Berlin: De Gruyter, 2012, p. 109-146.

MosegaARD, H. M.-B. The function of discourse particles: a study with special reference to spoken standard french. Amsterdam: John Benjamins, 1998.

RAMOS, R. As partículas modais como co-indicadores ilocutórios: o caso das perguntas retóricas. Actas do XV Encontro Nacional da Associação Portuguesa de Lingüística, v. 2, Braga: Associação Portuguesa de Lingüística, 2000, p. 225-242.

SAID ALI, M. Meios de expressão e alterações semânticas. Rio de Janeiro: Livraria Francisco Alves, 1930.

SCHENNER, M.; SODE, F. Modal particles in causal clauses: the case of German weil wohl. In: ABRAHAM, W.; LEISS, E. (org.). Modes of Modality: modality, typology, and universal grammar. Series 49. London: John Benjamins Studies in Language Companion, 2014, p. 291-314.

SCHEMANN, H. Die Modalpartikel und ihre funktionalen Äquivalente: Untersuchung anhand des Deutschen, Französichen und Portugiesischen. Archiv für das Studium der neueren Sprachen, v. 219, 1982, p. 1-18.

SCHMIDT-RADEFELDT, J. Partículas discursivas e interacionais no português e no espanhol em contraste com o alemão. In: SCHMIDT-RADEFELDT, J. (org.). Semiótica e linguística portuguesa e românica: homenagem a José Gonçalo de Carvalho. Tübingen: Narr, 1993, p. 63-78.

SCHOONJANS, S. Modal particles: problems in defining a category. In: DEGAND,L.; PIETRANDREA, P.; CoRnILIE, B. (org.). Discourse markers and modal particles: categorization and description. Amsterdam: John Benjamins, 2013, p. 133-161.

SPERBER, D.; WILSON, D. Teoria da Relevância. Linguagem em (Dis)curso, Tubarão, v. 5, esp., 2005, p. 221-268.

TRAUGOTT, E. C. Discussion article: discourse markers, modal particles and contrastive analysis, synchronic and diachronic. Catalan Journal of Linguistics, Barcelona, v. 6, 2007, p. 139157.

VASKÓ, I.; FRETHEIM, T. Some central pragmatic functions of the Norwegian particles altsa and nemlig. In: SWAN, T.; WESTWIK, O. J. (org.). Modality in Germanic languages. Berlin: Gruyter, 1997, p. 233-292.

VILELA, M. Gramática da língua portuguesa: gramática da palavra, gramática da frase, gramática do texto/discurso. Coimbra: Almedina, 1999.

VILELA, M.; KocH, I. V. Gramática da língua portuguesa: gramática da palavra, gramática da frase, gramática do texto/discurso. Coimbra: Almedina, 2001.

WALTEREIT, R. Modal particles and their functional equivalents: a speech-act-theoretic approach. Journal of Pragmatics, Amsterdam, v. 33, n. 9, 2001, p. 1391-1417.

WALTEREIT, R. Different functions, different histories: modal particles and discourse markers from a diachronic point of view. Catalan Journal of Linguistic, Barcelona, 2007, p. 6180 .

WALTEREIT, R.; DetGes, U. Different functions, different histories. Modal particles and discourse markers from a diachronic point of view. Catalan Journal of Linguistics, Barcelona, v. 6, 2007, p. 61-80. 
AquinO, M. C.; ArANTES, P. C. C. - Partículas modais em alemão e seus equivalentes funcionais

WELKER, H. As partículas modais no alemão e no português e as equivalências de aber, eben, etwa e vielleicht. Dissertação (Mestrado em Linguística) - Universidade de Brasília, Brasília, 1990.

WEYDT, H. Abtönungspartikel. Die deutschen Modalwörter und ihre französischen Entsprechungen. Bad Homburg v.d.H. Berlin: Gehlen, 1969.

Recebido em 17 de setembro de 2019 Aceito em 9 de janeiro de 2020 